\title{
Factors Effected the Performance of Green Building in Madrasah Building Components
}

\author{
Agung Sedayu \\ Faculty of Science and Technology Maulana Malik Ibrahim State Islamic University of Malang \\ E-mail:uinsedayu@gmail.com
}

\begin{abstract}
Educational institutions in the form of madrasah have been growing rapidly in Indonesia. The madrasah is maneged by government and private institutions. This shows that public trust to madrasah as a place of spiritual and academic learning is increasing. Madrasah are supported by several building facilities in achieving the success of their learning activities. This study aims to determine the factors that influence the performance of green building in the Madrasah Al-Rifaie. A review of the determination of performance factors is green building with a background that green building for the present is a solution to the realization of buildings that do not damage the environment. The research results obtained 10 performance factors including Security, Safety and Healthy, Facilities Function, Aesthetics, Easiness and Accessibility, Reliability, Durability, Comfortable and Regularity, Availability and Capacity, and Environmentally-friendly. The average of the important level of 10 performance factors are in important scale (scale 4). The results of this analysis can be continued at the stage of data collection and further analysis.
\end{abstract}

Keywords: Building components, Green building, Madrasah, Performance factors, User

\section{INTRODUCTION}

Educational institutions in the form of madrasah have developed rapidly in Indonesia. The madrasah is maneged by government and private institutions. This shows that public trust to the madrasah as a place to learn spiritually and academically is increasing highly. Religious Minister Lukman Hakim Saifuddin in Conference Increase Education Based On Research (2015) at South Tangerang stated that public trust to the Islamic education is getting higher. The opportunities for extraordinary Islamic education are increasing. We can see the increasing trust of parents to look for religion-based education, especially Islam in supporting their children to school. On future now has been many developed the integratation between the Islamic education with modern boarding school system, despite the high cost of education. Madrasah as one of education institution in the form of school supported by several building facilities in achieving the success of their learning activities. The building facilitiesin madrasah should be reliable and have good performance in physical so that able to ensure the security and safety for the building user. School buildings that not resistant to disaster are very vulnerable in terms of security, not only threatening the soul of children, but the damage or destruction of physical infrastructure is a loss of economic assets to the country. The efforts to rebuild or repair it will require a large funding which can disrupting state finance and the economy in general (Ministry of Education and Culture, 2015). This study aims to determine the factors that influence the performance of green building in Madrasah Al-Rifaie Malang. A review of the determination of performance factors is a green building with the background that green building for the present is a solution to the realization of buildings that do not damage the environment.

\section{MATERIALS AND METHODS}

The method in this research $t$ is descriptive statistics by calculating the level of user importance to the performance of madrasah buildings. The research respondents were madrasah users consisting of religious teachers, students, and visitors. The scale of measurement of user importance includes,

$1=$ not important

$2=$ less important

$3=$ quite important

$4=$ important

$5=$ very important

Many previous researches are used as reference and comparison with this research will be conducted such as the research conducted by Sedayu (2018) which examines the priority of maintaining the reliability of sustainable construction at the Surabaya Ampel Mosque. The results of the study obtained the highest research variables at the level of user needs were ease and affordability in maintaining building construction components. The variable that is the highest priority for improvement is non-hazardous building material. The highest target is guaranteed design and configuration of a harmless construction system. A'yun and Rachmaniyah (2017) conducted research that aims to describe the concept of Islamic design and the nuances of Ottoman Turkey and apply Islamic themes to the nuances of Ottoman Turkey into buildings as representative of Islamic-based schools. The results of this study explain that the application of Islamic design concepts to the nuances of Ottoman Turkey can be 
applied to space elements such as walls, ceilings, window details, door details, space furniture design and aesthetic elements. The application of the design can be taken from the concept of color and typical form of Ottoman Turkey. Anggraeni (2017) conducted research to improve the quality of facilities and infrastructure, and encourage the achievement for students, teachers, and schools. The study generated conclusions about the existing ergonomics and anthropometry in general from European countries, so that can use $50 \%$ percentile size. Design planning should pay attention to the surrounding environment, because it can help planning that is environmentally friendly and energy efficient. Hambali (2016) aims for describe development a new building school and room class. The research conducted by Hambali used descriptive qualitative method. Busono (2011) conducted study to obtain some information and description about the basic education infrastructure and facilities based on standard facilities and infrastructure public schools/madrasah (Permendiknas 24 of 2007). This research resulted an illustration that most of the school building area is appropriate with the standard requirements.

\section{RESULTS AND DISCUSSION}

\section{Results of User Requirements}

The results of preliminary survey to 30 respondents obtain ten performance factors include Easiness and Accessibility, Reliability, Durability, Comfortable and Regularity, Availability and Capacity, and Environmentally-friendly

\section{Descriptive Analysis}

A descriptive analysis provides a global description of the results of the initial research. The results of the frequency description of the performance factors to the eight research variables are presented in the figures below. Figure 1 shows a graph of the level of user importance to the security with the first highest score is an important scale (scale 4) with $24.67 \%$, while the second highest score is a quite important scale (scale 3) with $21.33 \%$.

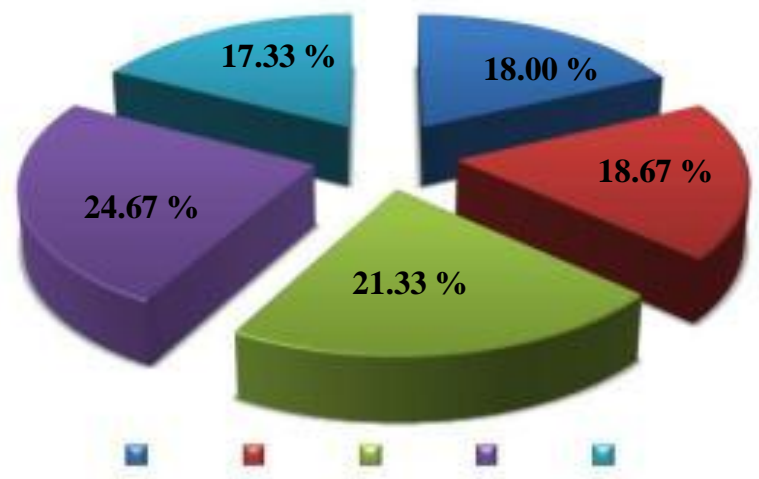

Figure 1. Graph of the level of user importance to security.
The graph of the level of user importance to safety factor is shown in Figure 2 with the first highest score is an important scale (scale 4) with $26.00 \%$ while the second highest score is a very important scale (scale 5) with a percentage of $21.33 \%$.
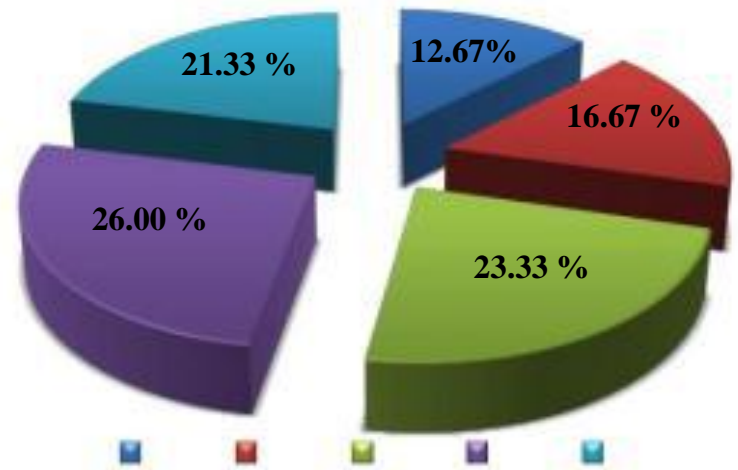

Figure 2. Graph of the level of user importance to safety and healthy.

The graph of the level of user importance to facilities function is shown in Figure 3, with the first highest score is an important scale (scale 4) with $26.67 \%$ while the second highest score is a very important scale (scale 5) with a percentage of $24.17 \%$.
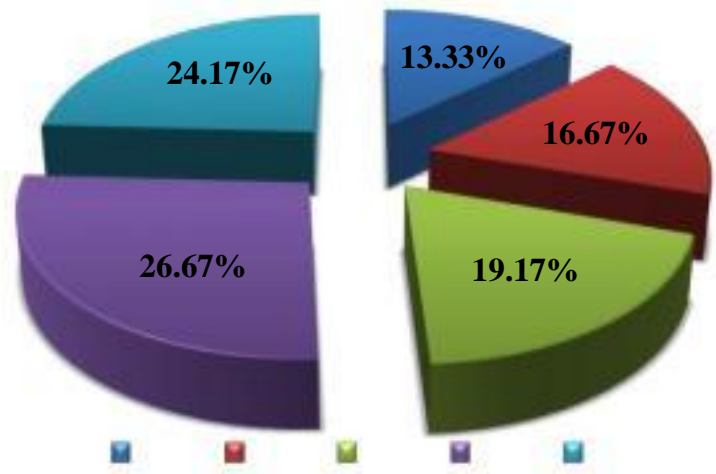

Figure 3. Graph of the level of user importance to facilities function.

The graph of the level of user importance to aesthetic is shown in Figure 4, with the first highest score is a quite important (scale 3) with $25.00 \%$ while the second score is an important scale (scale 4) with a percentage of $18.33 \%$.

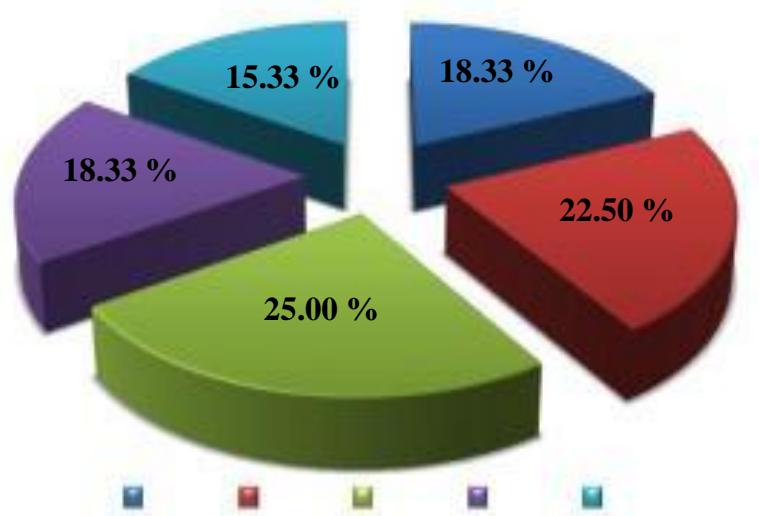

Figure 4. Graph of the level of user importance to aesthetics. 
Figure 5 is the graph of the level of user importance to easiness and accessibility. The results of the analysis for the first highest score is a quite important (scale 3) equal to $26.67 \%$, while the second highest score is an importance (scale of 4 ) with a percentage of $22.22 \%$.

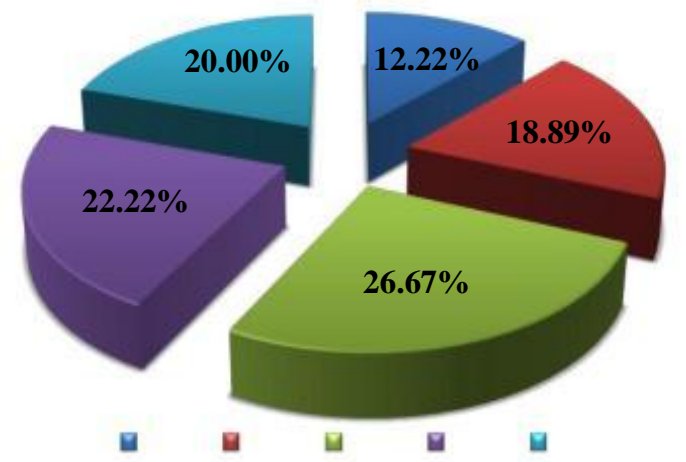

Figure 5. Graph of the level of user importance to easiness and accessbility.

Figure 6 is the graph of the level of user importance to reliability. The result of the analysis for the first highest score is an important scale (scale 4) equal to $26.67 \%$, while the second highest score is an importance (scale of 4 ) with a percentage $21.11 \%$.
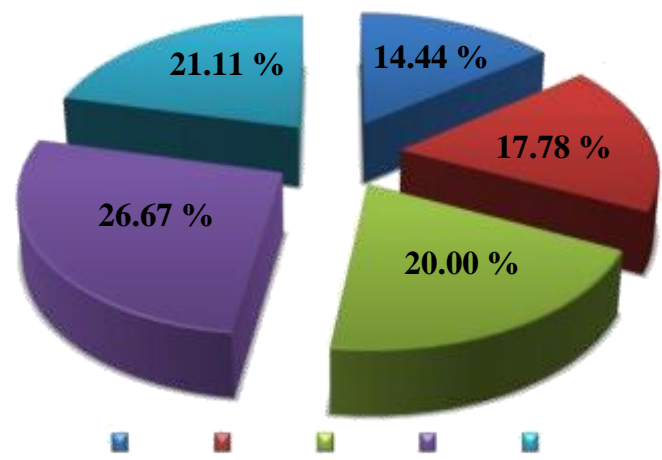

Figure 6. Graph of the level of user importance to reliability.

Figure 7 is the graph of the level of user importance to durability with the results of the analysis for the first highest score first is very important (scale 5) equal to $25.33 \%$, while the second highest score is an importance (scale 4) with a percentage of $23.33 \%$.

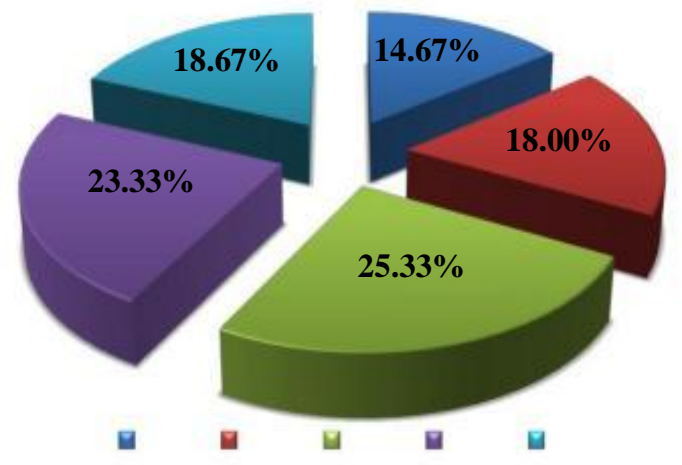

Figure 7. Graph of the level of user importance to durability.
The graph of the level of user importance to comfortable and regularity is shown in Figure 8. The first highest score is quite important (scale 3) with $22.73 \%$, while the second highest score is an importance (scale 4 ) with a percentage of $21.82 \%$.

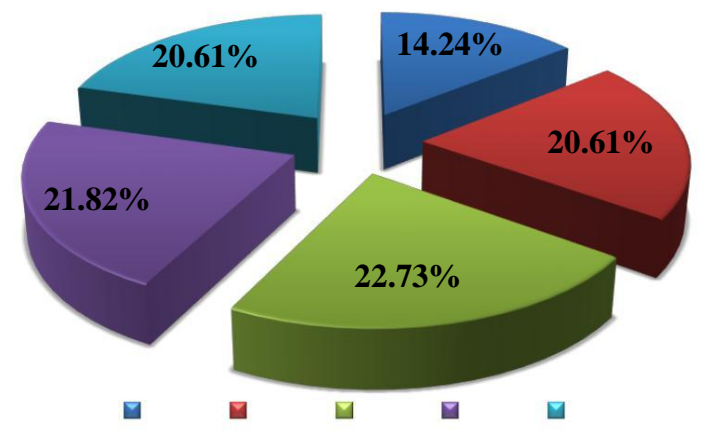

Figure 8. Graph of the level of user importance to comfortable and regularity.

The graph of the level of user importance to availability and capacity is shown in Figure 9, with the first highest score is an importance (scale 4) equal to $26.00 \%$, while the second highest score is very important (scale 5) with a percentage of $23.33 \%$.
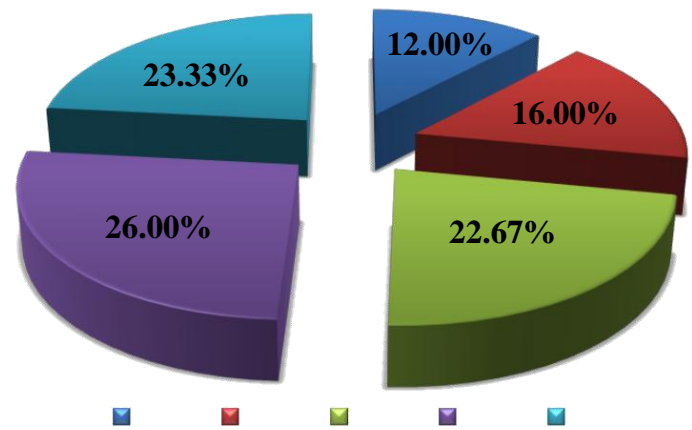

Figure 9. Graph of the level of user importance to availability and capacity.

The graph of the level of user importance to environmentally friendly is shown in figure 10 with the first highest score is an important (scale 4) with 26.39 $\%$, while the second highest score is a quite important (scale 3) with a percentage of $23.33 \%$. Overall for 10 performance factors, the average scores are an important scale (scale 4). The results of this analysis can be continued at the stage of data collection and further analysis.
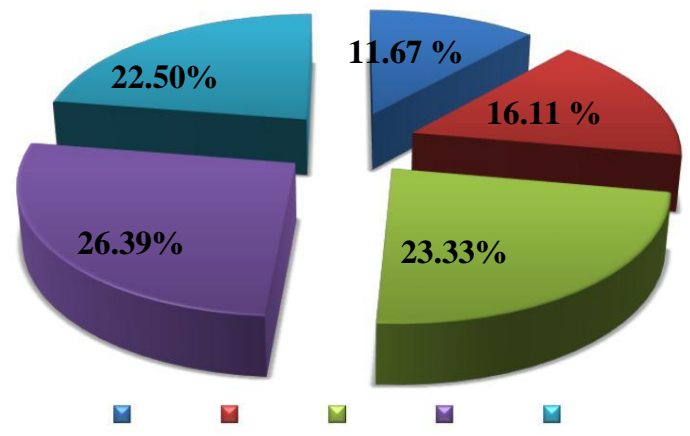

Figure 10. Graph of the level of user importance to environmentally friendly. 


\section{CONCLUSIONS}

The results of preliminary survey to 30 respondents obtain ten performance factors include Easiness and Accessibility, Reliability, Durability, Comfortable and Regularity, Availability and Capacity, and Environmentally-friendly. A descriptive analysis provides a global description of the results of the initial research. The level of user importance to the security with the first highest score is an important scale (scale 4) with $24.67 \%$, while the second highest score is a quite important scale (scale 3) with $21.33 \%$. The level of user importance to safety with the first highest score is an important scale (scale 4) with $26.00 \%$ while the second highest score is a very important scale (scale 5) with a percentage of $21.33 \%$. The level of user importance to facilities function with the first highest score is an important scale (scale 4) with $26.67 \%$ while the second highest score is a very important scale (scale 5) with a percentage of $24.17 \%$. The level of user importance to aesthetic with the first highest score is a quite important (scale 3) with $25.00 \%$ while the second score is an important scale (scale 4) with a percentage of $18.33 \%$. The level of user importance to easiness and accessibility generates the results of the analysis for the first highest score is a quite important (scale 3) equal to $26.67 \%$, while the second highest score is importance (scale of 4 ) with a percentage of $22.22 \%$. The level of user importance to reliability generates the result of the analysis for the first highest score is an important scale (scale 4) equal to $26.67 \%$, while the second highest score is importance (scale of 4) with a percentage $21.11 \%$. The level of user importance to durability with the results of the analysis for the first highest score first is very important (scale 5) equal to $25.33 \%$, while the second highest score is importance (scale 4) with a percentage of $23.33 \%$. The level of user importance to comfortable and regularity generates the first highest score is quite important (scale 3) with $22.73 \%$, while the second highest score is importance (scale 4) with a percentage of $21.82 \%$. The level of user importance to availability and capacity with the first highest score is an importance (scale 4) equal to $26.00 \%$, while the second highest score is very important (scale 5) with a percentage of $23.33 \%$. The level of user importance to environmentally friendly with the first highest score is an important (scale 4) with $26.39 \%$, while the second highest score is a quite important (scale 3) with a percentage of $23.33 \%$. Overall for 10 performance factors, the average scores are an important scale (scale 4). The results of this analysis can be continued at the stage of data collection and further analysis. The average of the important level of 10 performance factors are in important scale (scale 4). The results of this analysis can be continued at the stage of data collection and further analysis.

\section{REFERENCES}

Saifuddin, Lukman Hakim. 2015. Community trust to Islamic education is increasing highly. Greetings at the Opening of the Conference on writing the First Scientific Work at the Multipurpose Building, Madrasah Insan Cendekia Serpong, Banten pada 20 Oktober 2015. www. kemenag.go.id

Author Team. 2015. Module 1 Pillar 1 - Security School facilities. Bureau of Foreign Planning and Cooperation Ministry of Education and Culture Secretariat General Jakarta

Sedayu A. 2018. The priority of maintaining the reliability of sustainable construction at the Ampel mosque Surabaya, MATEC Web of conferences (indexed by Scopus)

A'yun SQ, Rachmaniyah N. 2017. Application of Ottomans Turkish nuance concept in the interior of the madrasah Mambaul Hasan Al-Misbah Paiton, Probolinggo. Journal of Sains Dan Seni Pomits Vol. 6, No. 2 (2017) 2337-3520 (2301-928X Print)

Anggraeni LK. 2017. Study on the application of ergonomics in the design of elementary school buildings, a case study in SDN Bubutan IV Surabaya. Journal of Interior Design Vol. 2, No. 1, Juni 2017, pISSN 2527-2853, eISSN 2549-2985

Hambali. 2016. Construction process of new school buildings and classrooms in Seluma district after after area development. Manajer Pendidikan, volume 10, no. 1, march 2016, page 20-28

Busono T. 2011. Evaluation of the fulfillment of minimum standards for basic education facilities and infrastructure in the city of Bandung. Invotec Volume VII, No. 1, February 2011: 81 -91 